\title{
Ethical issues encountered by medical school students during the physical examination of female genitalia
}

Müesser Özcan ( $\nabla$ muglabiyomer@gmail.com )

Mugla Sıtkı Kocaman University https://orcid.org/0000-0002-2401-7101

Emine Neşe Yeniceri

Mugla Sitki Kocman Universitesi Tip Fakultesi

Mert Küçük

Mugla Sitki Kocman Universitesi Tip Fakultesi

Research article

Keywords: medical students, physical examination, ethics

Posted Date: August 15th, 2020

DOI: https://doi.org/10.21203/rs.2.10506/v2

License: (c) (i) This work is licensed under a Creative Commons Attribution 4.0 International License.

Read Full License 


\section{Abstract}

Background The aim of the study was to identify the ethical issues encountered during the physical examination of the female genitalia, which can be deemed culturally intimate, by medical school students who have practiced genital examination so far on a limited number of models and find out the reasons of such issues. Methods The study was conducted with 120 voluntary medical school students in clinical years who completely filled out and delivered the forms. Results Students stated that while performing genital examinations on real patients during their clinical years, they faced various issues including the importance of taking patient's consent, disclosing their identity and proficiency, fearing to harm the patient due to lack of knowledge and skills, failing to perform genital examination, and having emotional problems. The rate of encountering such problems differed depending on students' gender and grade. Conclusions In clinical education, while they are equipped with self-confidence and proficiency, students should also be integrated in an environment where patient's comfort, ethical principles and values are preserved. This subject should be examined when ethical dilemmas constrain learning. In order to avoid ethical concerns during this process and ensure that the process can be managed positively by both parties, medical schools should put forth official policies and guidelines concerning the practice of genital examination in particular which is considered intimate by patients and share such policies and rules with both parties.

\section{Background}

Physical examination serves as a unique learning tool and clinical experience for medical school students 1 . Although physical examination to be performed by the student is educational for the student, it is not for the clinical benefit of the patient. In fact, a physical examination performed by a student is usually troublesome for the patients. Patients' consent to undergo a physical examination to be performed by a student is considered to be an indicator of self-sacrifice/cooperativeness for the sake of medical education. It is an ethical duty expected form the medical team to make an honest explanation to the patient in return for such self-sacrificing attitude2. For example, failure to disclose the student's identity causes the patient to consider him/her to be a competent physician, which means violation of integrity principle and thus casts a shadow over the fiduciary relationship between the physician and doctor-patient relationship based on trust3,4.

If a medical student will be present during the physical examination, the student should first be introduced to the patient by the specialist or the relevant assistant professor. Patients may have concerns regarding medical students' lack of experience, and they may reject a student's presence in any procedure whatsoever due to their fear and concern, which is within the autonomy of the patient and considered among the fundamental patient rights 5 .

Patients should be informed that medical education is based on clinical practice) and must definitely be provided as bed-side training and that not only the patient's autonomy but also the student's right to receive qualified education should be respected. It should also be reminded that patients are also 
responsible for contributing medical education. However, Patients must not be put under pressure for examination. Patients have a right to refuse to undergo an examination and their decision should be respected 6 .

Sometimes, physical examination triggers the patient's sense of intimacy, which requires the physician to be more careful. It is known that patients applying to Gynecology and Obstetrics or Urology Departments are more bothered by the presence of students. Thus, they may reject their presence during the examination. In the event that the patient does not clearly reject the presence of the medical student, it should be observed whether the patient still has trouble' 4,5,7. Due to the reasons stated above, medical students may prefer not to disclose the fact that they are students.

Various international specialty societies have issued guidelines which emphasize the requirements to inform the patient about the importance of the physical examination performed by students with regard to medical education and the role of all persons participated in the process. In addition, medical students are reminded of avoiding false or misleading statements about their identity and qualifications 8 .

Although there are a number of educational benefits to be received by students, any kind of trouble to be experienced by patients should be avoided during such an intimate examination. Being successful in handling difficulties will enable students to become better physicians who are more sensitive, empathetic and capable of understanding both their own and patients' needs 9,10.

Although such teaching models as simulations and employing professional patients have recently been beneficial educational means for students, this does not change the fact that students will ultimately encounter with real patients. Students may sometimes face ethical problems and/or dilemmas with patients whether under the guidance of their instructor physical examination $r$ or on their own. This study aims to identify the ethical issues encountered during the physical examination of female genitalia, which can be deemed culturally intimate, by medical school students who have practiced genital examination so far on a limited number of models and find out the reasons of such issues.

\section{Methods}

Sample and Data Collection Procedures: This study was carried out with 120 students enrolled to the Faculty of Medicine at Muğla Sıtkı Koçman University who are in the 4th, 5th and 6th year and who volunteered to the study and completely filled out and delivered the forms. Eleven students did not deliver the forms whereas eight students did not fill out them completely and were excluded from the study. All students included in this study completed their gynecology internship. These students only performed physical examination by means of a limited number of practices on models. The faculty of medicine where this study was carried out has not yet employed standardized patient simulations and lacks a simulation laboratory.

Ethical approval for this study was obtained from the Ethics Committee of Muğla Sıtkı Koçman University and the study was carried out upon the permission obtained from the deanery of the Faculty of Medicine. 
Survey Instrument: A literature review was performed with relevant specialized researchers and a questionnaire form was created. This questionnaire consisted of 35 questions which included demographic features excluding personally identifying information. Five -point Likert scale was used to obtain participants' opinions concerning the importance of female genitalia examination in terms of education and the importance of taking patient's consent prior to female genitalia examination. Participants were asked to answer these Likert-type questions by choosing among the items 1 . Unimportant, 2. of little importance, 3. Moderately important, 4. Important, and 5. Very important. The questionnaire also involved the following questions: Have you or your instructor ever encountered one of the following situations after asking for the patient's consent? If any, what sort of trouble have you had during female genitalia examination process? What was your reaction when you asked for permission for the female genitalia examination and got rejected by the patient? In your opinion, what is the best way for a medical student to learn how to perform a pelvic/rectal examination? Below these questions, participants were given some options to choose if they agreed. Participants were free to choose as many options as they wish as long as they agree. Since participants were allowed to choose more than one option, the cumulative frequency was found to be over $100 \%$. In addition, a blank area was provided under the "Other" heading so that the participants could express their opinions as they wish.

Statistical Analysis: Averages, standard deviations, frequencies and percentages were calculated. Chisquared test was used in the comparison of the categorical data and $p<0.05$ was considered to be statistically significant.

The purpose of the study was explained to the students in the study group and the students responsible for the internship group distributed the forms. The participants were asked to deliver the forms once they completed the questionnaire.

\section{Results}

The average age of the participants was found to be $23.11 \pm 1.26$. Participants consisted of $47(39.2)$ female and 73 (60.8) male students. A total of 120 students from the 4 th year ( $n=47,39.2 \%)$, the 5 th year $(n=41,34.1 \%)$ and the 6th year $(n=32,26.7 \%)$ participated in the study. All participants completed their Obstetrics and Gynecology assigned in the 4th year. Majority of the participants ( $n=97,81.5 \%$ ) reported that patient's consent prior to clinical or physical examination is required. However, $18.5 \%$ reported that patient's consent prior to physical examination is not required or they had no knowledge. Almost one-third of the participants ( $n=42,35 \%)$ was of the opinion that patient's consent is not required for the student to be present as an observer at the physical examination (Table 1). Most of the students $(n=89,74.2 \%)$ were told by an instructor before the clinical examinations how to behave during an examination, how to obtain patient's consent and what to do unless the patient gives his/her consent. In addition, one-fourth of the students $(25.8 \%)$ asserted that the instructor did not inform them, or they did not remember being informed on these matters (Table 1). 
Only half of the students $(n=59,49.6 \%)$ were found to know that patients have the right to reject the examination to be performed by a student. Most of the participants $(n=73,73.8 \%)$ stated that patients do not have the right to reject the student's presence during the examination or they do not have any idea on this matter (Table 1).

Although all of the participant completed their Obstetrics and Gynecology assigned in the 4th year, almost one in five of them $(n=26,21.7 \%)$ stated that they have never performed a genital examination at the clinic (Table 2).

It was determined that, almost half of the participants $(n=39,41.5 \%)$ did not clearly inform the patient about that they were students prior to genital examination. $77 \%$ of the students stated that the patients were asked for their consent prior to genital examination by the student or the instructor. There was a significant relationship between asking for patient's consent and gender. Male students asked for patient's consent at a higher rate compared to female students $(p=0.01)$. Majority of the students $(n=106$, $88.3 \%$ ) believed that it was easier for the female students to obtain female patients' informed consent prior to genital examination. One-third of the students $(n=42,35.3 \%)$ stated that if they were the patient, they would not accept undergoing a rectal/genital examination performed by a student of the opposite gender (Table 2).

When participants were asked whether they have faced a negative situation after asking for the patient's consent for the physical examination to be performed by them, more than one-third of the participants $(n=44,36.7 \%)$ were found to have encountered patients who rejected to undergo an examination to be performed by a student. Almost half of the students $(n=57,47.5 \%)$ encountered patients who did not want the student to be present at the room during the examination. In addition, half of the students $(n=59$, 49.2\%) encountered patients who showed their discomfort by their body language although they accepted undergoing an examination by a student (Table 3 ).

Table 4 shows the answers given by the students to the question what your reaction to the female patients was who refused when they were asked for permission for genital examination. The most frequent answer to this question was "I respected the patient's refusal but still got upset." (Table 4).

A small number of participants $(n=13,10.8 \%)$ were found to perform genital examination on an anesthetized/unconscious female patient. Majority of the participants $(n=48,58.5 \%)$ stated that they have never witnessed that a patient was asked for her consent prior to undergoing an examination being anesthetized/unconscious. Almost one-fourth of the participants $(n=30,25.49 \%)$ stated that they would never perform a genital examination on a patient in this situation; however, the majority $(n=68,57.6 \%)$ said they would accept it anyway (Table 5).

Table 6 shows the responses given to the question "If you had any troubles during a genital examination of a female patient, what sort of trouble was that?". Most frequent answers to this question were found to be "I was afraid of hurting the patient" and "I was afraid of that the patient would refuse my presence in the room during the examination". 
Majority of the participants $(n=100,83.3 \%)$ were found to have witnessed that the patients had emotional troubles during genital examination (Table 7). There was a statistically significant relationship between being aware of the patient's emotional trouble and gender. Female students had witnessed patients' emotional trouble more than males did $(p=0.015)$. The results differed numerically depending on the grade; however, it was not statistically significant. Similarly, almost one-third of the participants $(n=39$, 33.1\%) stated that they also had emotional troubles during the genital examination of female patients. A statistically significant relationship was detected between this result and gender. Having emotional troubles during the genital examination of a patient was reported by female students more than males $(p=0.029)$.

Almost half of the participants ( $n=51,43.2 \%)$ were found to encounter ethical problems in the genital examination process of female patients. The frequency of student's encounter with ethical problems during a genital examination varied according to their grade. This result suggests that the rate of encountering ethical problems increased among the students in higher grades. Frequency of encountering with ethical problems increased at fifth and sixth grades compared to fourth grade $(p=0.01)$.

The participants were asked what is the best way for a medical student to learn how to perform a pelvic/rectal examination. The most frequently given answers are, respectively, "It is totally a humane practice so can be performed on any clinical patient when necessary." "It is for the benefit of the student and thus should be considered a regular practice." and "The patient should allow because contributing to science is a human duty." (Table 8). In addition, six students stated they were of the opinion that "Pelvic examination should not be performed on humans for learning purposes". Moreover, 20 students (16.7\%) suggested that "It should be performed on anesthetized patients whose consent was taken to ensure that they don't feel discomfort." (Table 8). Majority of the participant (94.1\%) claimed that performing a genital examination on a female patient is of utmost importance for their education.

\section{Discussion}

Medical school students were found to have some ethical problems in the genital examination process of female patients during their clinical internship at various degrees depending on gender and grade. Almost one-fifth of the students believed that patient's consent for students' participation in a physical examination is not required whereas one-third does not consider it necessary for being present as an observer or stated that they did not have an idea. (Table 1).

Most women in Turkey were reported to feel anxiety, stress, fear and embarrassment with regard to undergoing gynecological examination. Physicians' failure to make explanations regarding the examination and attach importance to intimacy may result in negative experiences about such examinations and negatively affect the continuity of follow-up examinations 11 . Thus, women may feel uncomfortable with the presence of one or more students during the gynecological examination even if it was just for observation. It is a valuable help when patients allow students to touch their bodies only for 
learning purposes. Thus, the limits of this permit and the ethical liabilities of students towards the patients should be taken into account. Letting patients know that the examination will be performed or observed by students and obtaining their consent is of great importance in terms of ethics. In fact, students are first informed about the process of obtaining patient's informed consent at every stage of medical education and repetitively reminded of this duty before their internship. Still, some students did not remember being informed on that matter before internship by their instructor. Although this may stem from the students' own negligence, it would still be beneficial if the instructors remind them of their duty repetitively. On the other hand, unwillingness of clinical instructors to get the informed consent of patients especially due to their workload is thought to set a negative role model for the students.

A reason behind students' opinion that obtaining patient's consent is not necessary before examination may arise from their misconception that this is their instructor's duty rather than their own. Another reason is the dominance of the belief that the patients coming to training and research hospitals in particular have a "tacit" consent for all the procedures to be carried out by the medical team including the students. Students assume that patients applying to the hospital accept in advance all the procedures to be performed by the healthcare professionals. If students fail to obtain patient's consent prior to examination based on such assumption, this would result in a serious ethical problem. 12. Including ethical issues regarding patient's consent in every phase of medical education is important. However, students need to embody this knowledge in their attitudes and behaviors. To this end, Elçin et al. developed an assessment tool to find out whether the students will embrace an ethical approach before performing examination and obtaining the consent of the patient who applied to the hospital due to a gynecological complaint.

A considerable number of students was of the opinion that patients did not have the right to reject the presence of a student in the physical examination (Table 1). The key element of ethical approach is respect for the patient. Patients have the right to refuse undergoing an examination to be performed by a student. Thus, before the examination, permission must be obtained from the patient with regard to the presence of the student. Students should definitely get permission from patients before the examination 4. Physical examination which can be considered intimate by patients mostly refers to the examination of very intimate or sensitive body parts. Performing the examination of sensitive body parts on real patients brings about some challenges in medical education. Although such teaching models as simulations and employing professional patients have recently been beneficial educational means for students, this does not change the fact that students will ultimately encounter with real patients. Sometimes, students may be more timorous and less willing in this process. Among the study results revealing that almost one-fifth of the students have never performed genital examination at the clinic supports this fact (Table 2). This result was indicative of the fact that the students were likely to graduate without performing genital examination on a real patient even for once. However, performing genital examination on a real patient allows students to experience different aspects of learning. Of course, it is the duty of medical instructors to ensure that the students are completely ready in terms of both knowledge and skills and more selfconfident and willing when they encounter a real patient. The results of the study carried out by Siwe et al. in order to compare the two models of genital examination, namely the ones performed on 
professional patients and clinical patients, highlights the importance of this situation. It was revealed that when students perform physical examinations on professional patients before they encounter clinical patients, their self-confidence increases, examination skills enhance, they become more competent and perform more genital examinations during clinical internship 13. Another study carried out at Maastricht University with fourth and fifth grade students evaluated the effects of learning with standardized patients. Working with standardized patients improves students' communication skills, self-confidence, gynecological examination skills, interaction with patients, ability to give constructive feed-back to the patient 14.

The study revealed that almost half of the students fail to disclose their identity to patients. As known, patients have the right to know the identity and professional status of the person who provides health care. In general, students are inclined to introduce themselves, explain their positions and take consent regardless of the invasiveness of the procedure. According to the results of some studies, students see themselves as a part of the medical team and are worried about being rejected by the patient. Thus, only a small number of them introduce themselves as "doctors". In fact, mostly the other members of the medical team introduce the students as "doctors". The justification behind resorting to such deception is told to be the fear that the clinical education would be jeopardized in case of the patient's refusal 4 . Medical instructors also have similar concerns and even believe that such rejections sadden students and cause them to lose their motivation. It is a matter of debate that balancing the ethical duties and educational needs in ethical approach in terms of intimate area examinations is challenging and although students need to learn, patients also need to be protected 4. It was detected that almost half of the students encountered patients who either rejected or showed their discontent although they gave their consent (Table 3). While students frequently stated that they felt upset in the face of such rejections, majority of them claimed that their instructors convinced the patients by an appropriate communication (Table 4), which suggests that the instructors mostly focus on students' learning. Various studies evaluated the reasons why patients refuse to undergo an examination to be performed by a student. For instance, a study carried out at the University of California with 180 patients revealed that patients in gynecology polyclinics accept the examination to be performed by a student because they want to contribute to education and allow future physicians to attain a higher level of standard of care. Protection of patient's intimacy and low levels of comfort during the examination process were provided as rejection reasons. Similar studies revealed that concerns about the occupational proficiency of students and intimacy due to their gender are among the reasons provided by the patients who rejected such genital examination $4,7,15$.

It has been discussed that whether the genital examination on anesthetized patients who have already given their consent would be an alternative learning method concerning especially the fear of rejection and comfort of patients. In recent years, it is observed that studies on the ethical aspect of physical examination practices on the anesthetized patients are intensified. In this study, it was found that performing genital examination on anesthetized patients who have given their consent for a genital examination to be performed by a student was recommended as a good learning method. In addition, it was determined that a small percentage of the participants $(n=13,10.8 \%)$ performed genital examination 
on an anesthetized/unconscious female patient without being sure whether she has given her consent (Table 5). Patients are informed about they will undergo a genital examination performed by a student and their consent is obtained before they are anesthetized. It is highlighted that students should know such physical examinations can be performed in the case that the patient has given her consent 16 . The American Medical Association and the Association of American Medical Colleges reported that they do not find genital examinations to be performed by students on anesthetized patients ethically appropriate without their consent. Authors insistently asked why patients are not asked for their consent and stated that there are studies on this subject indicating more than half of the women gave their consent when they were asked 17. Studies revealed that more than half of the women their consent for such examinations when they are asked.Procedure of obtaining patients' consent allows students to learn the value of the patient's autonomy and the trust between patients and physicians 17 .

Students have concerns with regard to performing genital examination as well. Their first examination in particular may be a traumatic experience for them. Such intense concern especially reduces the educative quality of the first examination. The students who participated in our study stated that they mostly had emotional troubles due to their fear of hurting the patient and being rejected (Table 6). According to the results of other studies on this subject, students are afraid of hurting the patient, being judged, being found unskillful, failing to make a diagnosis; rarely feel embarrassed, lack of self-confidence; and, found the procedure unpleasant due to the belief that women dislike the pelvic examination 4,7.

Gender sometimes may be a positive or negative factor for students with regard to physical examination of intimate areas. Most of the students participating in this study were of the opinion that gender is an important factor in genital examination, being female is advantageous and the procedure is more challenging for males (Table 2). The results of the studies carried out in Turkey with the participation of senior students show that female students perform breast and genital examination of women more than male students whereas male students perform prostate examination more 18. Similar results obtained in a study conducted at the University of Washington School of Medicine with the participation of 402 third and fourth grade students. Gender of the student is an important factor in the intimate examination for the opposite gender 5 . A three-year long study carried out with 355 medical school students in US evaluating students' academic performance in obstetrics and gynecology revealed that female students delivered a better performance and got higher practice exam results than their male counterparts 19 . In a study carried out in Pennsylvania, patients rejected male students more. Male students felt that their gender negatively affects their learning of physical examination. Male students also claimed that they felt socially excluded due to the female dominance and gender prejudice in gynecology units 20 . According to the results of another inclusive study which also included physicians, age of patients and the gender of medical students are determinant factors in patients' acceptance of the examination. There were patients, even in small numbers, who are prejudiced towards undergoing an examination by a male student 21. In the study conducted at University of California, patients mostly accepted to undergo an examination performed by female students 15 . It is told that some female patients attach great importance to physicians' gender and prefer a physician of the same gender. Such preference is told to be 
dominated by the belief that the physician's gender protects the intimacy in some intimate area examinations and renders the examination psychologically tolerable22.

Gender-based rejection was effective also in the preferences of students participating in this study. Onethird of the students stated that if they were the patient, they would not accept undergoing a rectal/genital examination performed by a student of the opposite gender (Table 2). However, most of the students were of the opinion that patients have to give consent for the sake of genital examination education.

Many students believed that the pelvic examination is a humane practice, should be performed on any patient when necessary, and is a regular practice which is for the benefit of the student and it is a duty of humans for the contribution to science so the patients should give permission. In this regard, it is thought that students do not sufficiently empathize with patients and they should ask themselves what they would think if they were the patient. Moreover, most of the students had witnessed that patients had emotional troubles (Table 7). Almost one-third of the students reported that they also had emotional troubles when they performed genital examination on a patient (Table 7). It is known that medical students feel discomfort during the examination of intimate areas. Therefore, it is suggested that such examinations should be taught on simulation models at the beginning 23. Traditional education mostly focuses on technical skills rather than social and psychological aspects of the examination of intimate areas 7 . In simulation models, providing students with the opportunity to practice how to inform the patient, speak to them in a comforting manner, and obtain their consent along with technical education is thought to decrease the problems to be faced by the students during these practices. Some medical schools issued guidelines taking into account the ethical standards for the examination of intimate areas in particular and clinical education. Thus, awareness concerning relevant ethical and legal standards can be raised among students, instructors and patients 4 . Students stated that physical examination is completely a humane practice which can be performed by students when necessary on any clinical patient as well as that patients should consider such examinations to be regular practices which are for the benefit of the student and the duty of humans that will contribute to science. In addition, students believed that examination on real patients is the best way through which a medical student can learn how to perform a pelvic/rectal examination (Table 8). There are some limitations in terms of obtaining feedbacks from patients about their discomforting feelings in particular when genital examination education is provided through performing such examinations on real patients. Thus, students are advised to hold a preliminary communication with standardized patients which will allow them to confront their own feelings and patients' possible feelings before encountering real patients $4,7,24$. Some medical schools issued guidelines taking into account the ethical standards for the examination of intimate areas in particular and clinical education. Thus, awareness concerning relevant ethical and legal standards can be raised among students, instructors and patients 4 .

\section{Conclusion}


Genital examinations performed on real patients is an important learning experience in medical education through which students can improve their physical examination skills and obtain clinical knowledge. They also experience how to establish a delicate and sincere relationship with patients, discover the emotional impacts of examining especially the patients of the other sex on them and learn how to overcome such impacts. Being successful in handling difficulties will enable students to become better physicians who are more sensitive, empathetic and capable of understanding both their own and patients' needs.

However, there are some constraints to genital examination education through real patients. It can be claimed that it is difficult to balance student participation and efficiency of the education in the examination of intimate areas. Students and instructors should act responsibly and consider their ethical responsibilities to protect the patients when they pursue the educational needs. This sort of examination has an intimate nature and sometimes students' participation in the examination process may distort the nature of the relationship between the patient and the physician, and thus result in various ethical problems. Problems frequently encountered such as whether to get patient's consent, honesty in terms of explaining one's own identity and proficiency, fear of hurting the patient due to lack of knowledge and skills, and gender-based discrimination may pose some challenges in performing such ethical duties as protecting patient's autonomy and acting for the benefit of the patient.

Thus, when providing clinical education for students, all other learning approaches should be adopted in order to improve their skills enabling them to gain self-confident and competency and they should be integrated in an environment where patient's comfort, ethical principles and values are preserved. In clinical education, while they are equipped with self-confidence and proficiency, students should also be integrated in an environment where patient's comfort, ethical principles and values are preserved. Instructors who are responsible of clinical practices should identify possible problems by evaluating such physical examination processes in terms of patients and students. Education of students which involves the sensitive nature of physical examination and ethical issues it raises should be supported by guidelines observing patients' rights and well-being and these rules should be shared with both parties to ensure the process is managed positively for them both.

\section{Declarations}

\section{Ethics approval and consent to participate}

This study was carried out during the 2018 academic year among the medical students in Mugla Sıtkı Kocman University, The Faculty of Medicine. Students were informed about the study, and voluntary participation was obtained. Data were collected through the use of anonymous questionnaire, and the students were reminded that returning a completed study form implies informed consent. The study was approved by the Institution's Mugla Sıtkı Kocman Ethics Committee on January $24^{\text {th }}$, 2018, with an approval number of 170074-05. 


\section{Competing interests}

The author(s) declare no potential conflicts of interest with respect to the research, authorship, and/or publication of this article

\section{Authors' contributions}

All authors contributed to the conception and design of this study, to the acquisition and analysis of the data, to the drafting and revision of this paper and each has given final approval to this version of the paper.

\section{Acknowledgments}

The authors would like to thank all students who participated in the study.

\section{References}

Dull P, Haines DJ. Methods for teaching physical examination skills to medical students. Fam Med. 2003; 35: 343-348.

Ziv A, Wolpe PR, Small SD, Glick S. Simulation-based medical education: an ethical imperative. Acad Med. 2003; 78: 783-788.

Branch WT. Supporting the moral development of medical students. J Gen Intern Med. 2000;15: 503-508.

Coldicott $Y$, Nesheim Bl, MacDougall J, Pope C, Roberts $C$. The ethics of intimate examinations-teaching tomorrow's doctors Commentary: Respecting the patient's integrity is the key Commentary: Teaching pelvic examination-putting the patient first. BMJ, 2003;326: 97-101.

https://doi.org/10.1136/bmj.326.7380.97

Powell HS, Bridge J, Eskesen S, Estrada F, Laya M. Medical students' self-reported experiences performing pelvic, breast, and male genital examinations and the influence of student gender and physician supervision. Acad Med. 2006; 81, 286-289.

General Medical Council, 2008. Consent: patients and doctors making decisions together https://www.gmc-uk.org/-/media/documents/consent-. (accessed 12 October 2019).

Seago BL, Ketchum JM, Willett RM. Pelvic examination skills training with genital teaching associates and a pelvic simulator: does sequence matter? Sımul Healthc. 2012; 7: 95-101. https://doi.org/ 10.1097/SIH.0b013e31823b9e46

Santen SA, Hemphill RR, Spanier CM, Fletcher ND. 'Sorry, it's my first time!'Will patients consent to medical students learning procedures? Med Educ. 2005; 39: 365-369. https://doi.org/10.1111/j.1365-

2929.2005.02113.x 
Cordingley L, Hyd C, Peters S, Vernon B, Bundy C. Undergraduate medical students' exposure to clinical ethics: a challenge to the development of professional behaviours? Med Educ. 2007; 41: 1202-1209. https://doi.org/10.1111/j.1365-2923.2007.02943.x

Savulescu J. Ethics: Conscientious objection in medicine. BMJ. 2006;332: 294-

Demir S, Oskay YÜ. Jinekolojik muayene olan kadınların yaşadığı deneyimler ve sağlık profesyonelinden beklentileri. $\mathrm{EExperiences} \mathrm{of} \mathrm{women} \mathrm{with} \mathrm{gynecological} \mathrm{examinations} \mathrm{and} \mathrm{expectations} \mathrm{from} \mathrm{health}$ professionals $\rrbracket$. KASHED. 2014; 1:68-79. (In Turkish)

Elçin M, Büken NÖ.Tıp öğrencilerinin jinekolojik muayene yapmak için hastadan onam almalarının değerlendirilmesinde bir yöntem örneği. [An example of a method for evaluating medical students'

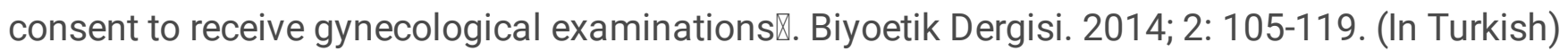

Siwe K, Wijma K, Stjernquist M, Wijma B. Medical students learning the pelvic examination: comparison of outcome in terms of skills between a professional patient and a clinical patient model. Patıent Educ Couns. 2007; 68: 211-217. https://doi.org/10.1016/j.pec.2007.05.007

Bokken L, Rethans JJ, van Heurn L, Duvivier R, Scherpbier A, van der Vleuten C. Students' views on the use of real patients and simulated patients in undergraduate medical education. Acad Med. 2009; 84: 958-963.

Ching SL, Gates EA, Robertson PA. Factors influencing obstetric and gynecologic patients' decisions toward medical student involvement in the outpatient setting. AMJ Obstet Gynecol. 2000; 182:1429-1432. https://doi.org/10.1067/mob.2000.106133

Ubel PA, Jepson C, Isenstadt AS. Don't ask, don't tell: a change in medical student attitudes after obstetrics/gynecology clerkships toward seeking consent for pelvic examinations on an anesthetized patient. Am J Obstet Gynecol. 2003;188: 575-579.

\section{https://doi.org/10.1067/mob.2003.85}

Barnes SS. Practicing pelvic examinations by medical students on women under anesthesia: why not ask first? Obstet Gynecol. 2012; 120:941-943. https://doi.org/ 10.1097/AOG.0b013e3182677a28

Mistik S. Medıcal students'gender-specıfıc examınatıon performance. Soc Behav Personal. 2008; 36: 9991008. https://doi.org/10.2224/sbp.2008.36.7.999

Bienstock JL, Martin S, Tzou W, Fox HE. Medical students' gender is a predictor of success in the obstetrics and gynecology basic clerkship. Teach Learn Med. 2002; 14: 240-243. https://doi.org/10.1207/S15328015TLM1404_7 
Chang JC. Odrobina MR, McIntyre-Seltman K. The effect of student gender on the obstetrics and gynecology clerkship experience. J Womens Health. 2010; 19: 87-92.

https://doi.org/10.1089/jwh.2009.1357

Mavis B, Vasilenko P, Schnuth R, Marshall J, Jeffs MC. Medical students' involvement in outpatient clinical encounters: A survey of patients and their obstetricians-gynecologists. Acad Med. 2006; 81:290296.

Wang YJ, Yang J, Kang LX, Jia Z, Chen DM, Zhang P, Feng ZC. Acceptability of physical examination by male doctors in medical care: Taking breast palpation as an example. J Huazhong U ScI-Med. 2015; 35: 781-784.

Dabson AM, Magin PJ, Heading G, Pond D. Medical students' experiences learning intimate physical examination skills: a qualitative study. BMC Med Educ. 2014; 14:39-47. https://doi.org/10.1186/14726920-14-39

Bell K, Boshuizen HP, Scherpbier A, Dornan T. When only the real thing will do: junior medical students' learning from real patients. Med Educ. 2009; 43:1036-1043. https://doi.org/10.1111/j.13652923.2009.03508.x

\section{Supplementary Files}

This is a list of supplementary files associated with this preprint. Click to download.

- TABLES.docx 